\title{
MODELAMENTO, ANÁLISE E VALIDAÇÃO DO PROCESSO DE LAMINAÇÃO DE ENCRUAMENTO PELO MÉTODO DOS ELEMENTOS FINITOS
}

\author{
Yukio Shigaki ' \\ Jonatas Mezêncio Silva ' \\ Rafael Narciso Alvarenga Romie ' \\ Sandro Cardoso Santos
}

\section{Resumo}

Diversos modelos matemáticos da laminação de encruamento foram desenvolvidos, porém poucos demonstram a distribuição de tensões no interior da tira dentro do arco de contato e após sair do mesmo. Os modelos desenvolvidos em elementos finitos permitem determinar essas tensões internas de forma bastante precisa. $O$ modelamento, porém, da laminação de encruamento em elementos finitos não é tarefa simples, envolvendo a aplicação correta das condições de contorno, entrada da propriedade do material da tira, discretização da chapa e principalmente do cilindro de trabalho e mais alguns ajustes numéricos. $O$ presente trabalho apresenta o modelamento da laminação de encruamento no programa de elementos finitos Simulia Abaqus explícito dinâmico, baseado em um laminador real industrial e resultados são comparados ao final. Ajustando-se o modelo obteve-se um valor de carga $0,2 \%$ menor que o medido. São feitas, também, considerações sobre o arco de contato e a distribuição interna de tensões.

Palavras-chave: Laminação de encruamento; Método dos elementos finitos; Simulação; Carga de laminação

\section{TEMPER ROLLING PROCESS MODELING WITH THE FINITE ELEMENT METHOD}

\begin{abstract}
Several mathematical models of the temper rolling process have been developed, but only a few demonstrate the distribution of stresses inside the strip within the arc of contact and in the outgoing strip. The models developed in finite elements allow to determine these internal tensions in a very precise way. The modeling, however, of the finite element temper rolling process is not a simple task, involving the correct application of the boundary conditions, strip's material properties input, discretization of the strip and especially of the working roll and some numerical adjustments. The present work presents the temper rolling modeling in the finite element program Simulia Abaqus explicit-dynamic, based on an actual industrial temper rolling mill and results are assessed. Adjusting the numerical model a rolling load $0,2 \%$ less was obtained. Arc of contact profile and internal stresses of the strip are shown.
\end{abstract}

Keywords: Temper rolling; Finite element method; Simulation; Rolling load.

\section{INTRODUÇÃO}

O processo de laminação de encruamento a frio é uma das últimas etapas na produção de tiras finas e possui muitos propósitos. Caracteriza-se pela baixa redução aplicada sobre a tira, geralmente da ordem de 0,5 a I,5\%. A laminação de encruamento é realizada para melhorar a planicidade final da tira e suas propriedades metalúrgicas, eliminar o patamar de tensão de escoamento superior e inferior, obter um melhor acabamento superficial e, às vezes, favorecer o desenvolvimento posterior de propriedades magnéticas.

As condições na laminação de encruamento são diferentes de outros tipos de laminação a frio em laminadores reversíveis e contínuos. Como foi mencionado antes, a redução é muito baixa, a deformação do cilindro de trabalho

'Departamento de Engenharia Mecânica, Centro Federal de Educação Tecnológica de Minas Gerais - CEFET-MG, Belo Horizonte, MG, Brasil. E-mail: yukio.shigaki@cefetmg.br

2176-1523 (C) 2019 Associação Brasileira de Metalurgia, Materiais e Mineração. Publicado pela ABM. Este é um artigo de acesso aberto distribuído sob os termos da licença Creative Commons CC BY-NC-ND (Attribution-NonCommercial-NoDerivs) - https:// creativecommons.org/licenses/by-nc-nd/4.0\%. 
é muito localizada no arco de contato e há considerável restituição elástica da tira.

Essas diferenças tornam o cálculo da carga de laminação de encruamento extremamente difícil. Dentre os aspectos mais importantes, devem-se considerar: I - o comportamento da curva tensão-deformação do material da chapa, que é recozido, e que em baixas reduções é sensivelmente variável para diferentes taxas de deformação; 2 - o fato das reduções serem muito baixas em alguns casos, levando-se a comprimentos de arco de contato pequenos, provocando uma carga extremamente concentrada, o que leva a instabilidades nos modelos numéricos, requerendo uma estratégia de relaxação para as variações de carga e de perfil a cada iteração; 3 - espessuras reduzidas e reduções baixas que podem ser da ordem da rugosidade dos materiais envolvidos; 4 - a necessidade de se considerar a deformação elástica dos cilindros para se obter um resultado preciso; 5 - a possibilidade de haver dois regimes de atrito, o de deslizamento e de agarre, dentro do arco de contato, e a existência de uma região intermediária plana (hipótese ainda controversa) onde a deformação plástica é contida devido ao estado complexo de tensões.

Diversos modelos matemáticos foram desenvolvidos para a determinação da carga de laminação, por se tratar de um item fundamental no funcionamento dos sistemas de controle dos laminadores, porém, os utilizados para cálculo da carga de laminação, com exceção do método dos blocos e o método dos elementos finitos (MEF), dificilmente podem ser aplicados diretamente à análise do processo de laminação de encruamento por características específicas do processo de fabricação.

Assim, diversos autores sugeriram outros modelos semi-empíricos para o cálculo da carga de laminação, sendo o mais famoso o de Roberts [I]. Este modelo supõe que a pressão de contato no arco é semi-elíptica, sugere uma equação empírica para calcular a resistência à deformação da chapa e também um modo de estimar o comprimento do arco de contato entre o cilindro de trabalho e a chapa. Interessante observar que Roberts inclui a influência da taxa de deformação do material da chapa em suas equações, pois é sabida a sua influência sobre a carga.

Lenard, em seu livro [2] comenta sobre outros modelos matemáticos desenvolvidos para a modelagem da laminação de encruamento em que, resumindo:

- Os parâmetros mais importantes do processo são a tensão à ré e à frente, espessuras de entrada e de saída, parâmetros do material, velocidade de laminação, as condições de deslizamento no arco de contato, a carga de laminação e a dinâmica do laminador;

- Os modelos tradicionais de cálculo da carga de laminação não se aplicam na laminação de chapas finas, folhas e na laminação de encruamento, e que o fator mais importante é a maneira em que ocorre o acoplamento da deformação do cilindro de trabalho com a da tira;

- Existe uma grande dificuldade na modelagem desse processo devido à imprecisão no cálculo do deslizamento no arco de contato e no elevado tempo de processamento em elementos finitos;

- Existem modelos da laminação de encruamento em elementos finitos em combinação com redes neurais artificiais, conseguindo resultados precisos de carga, porém, surpreendentemente utilizando coeficientes de atrito bastante baixos.

Liu e Lee [3], Pawelski [4], Dbouk e colegas [5] e Noncirc [6] apresentam desenvolvimentos mais recentes sobre a modelagem da laminação de encruamento. O Método dos Elementos Finitos também tem sido utilizado na análise da laminação de encruamento. Podem-se citar os trabalhos de Kainz [7], Gratacos [8] e Shigaki [9]. A grande vantagem deste método em relação aos tradicionais baseados no método dos blocos reside no fato de se poder determinar a distribuição de tensões e deformações, perfil do arco de contato e da deformação dos cilindros e a carga de laminação com grande detalhe.

Neste estudo será apresentado um modelo bidimensional da laminação de encruamento via método dos elementos finitos (MEF). Este modelo baseia-se na hipótese de estado plano de deformação que ocorre na tira e no cilindro. Suas características e dimensões foram tomadas de um laminador industrial real, e os resultados para efeitos de validação do modelo numérico serão comparados a valores reais. Será apresentado o modelo em elementos finitos desenvolvido no software Simulia Abaqus versão 2016, com os detalhes da aplicação das condições de contorno, velocidades, tensões de tração à ré e à frente, curvas tensão-deformação da chapa, propriedades dos materiais dos cilindros, em especialmente, a estratégia de discretização da malha de elementos finitos. Por se tratar de dimensões bastante díspares entre a espessura da chapa e o diametro do cilindro de trabalho, - tamanho médio dos elementos das malhas da chapa e da região de contato no cilindro deve ser cuidadosamente escolhido. Alguns resultados da simulação também serão apresentados, com validação baseado em dados industriais.

\section{DESENVOLVIMENTO}

Neste item será descrito brevemente o modelo em elementos finitos desenvolvido no presente trabalho. Os dados industriais foram fornecidos por uma grande empresa siderúrgica brasileira. A Tabela I apresenta os dados da chapa e do equipamento.

As dimensões da geometria, definição dos materiais e condições operacionais do modelo estão listadas na Tabela I, sendo que o modelo é constituído por duas partes: o cilindro de laminação e a chapa. A simplificação para o 
caso bidimensional possibilita a modelagem do cilindro como um círculo e da chapa como um retângulo representando a metade da chapa em relação à espessura (simetria).

A geometria do cilindro foi particionada a fim possibilitar o refino de malha na região do contato com a chapa, além de possibilitar transição suave para áreas menos refinadas. As partições estão descritas na Figura I. O comprimento da chapa no modelo numérico é de $110 \mathrm{~mm}$.

As dimensões da geometria, definição dos materiais e condições operacionais do modelo estão listadas na Tabela I, sendo que o modelo é constituído por duas partes: o cilindro de laminação e a chapa. A simplificação para o caso bidimensional possibilita a modelagem do cilindro como um círculo e da chapa como um retângulo representando a metade da chapa em relação à espessura (simetria).

A geometria do cilindro foi particionada a fim possibilitar o refino de malha na região do contato com a chapa, além de possibilitar transição suave para áreas menos refinadas. As partições estão descritas na Figura I. O comprimento da chapa no modelo numérico é de $110 \mathrm{~mm}$.

Pode-se observar na Figura 2 a malha gerada na parte mais refinada, de contato entre a chapa e o cilindro. O tamanho de elemento utilizado no modelo foi de $0,025 \mathrm{~mm}$ para a chapa, 0,025 $\mathrm{mm}$ para região do cilindro em contato com a chapa, 0, I mm para área acima da região de contato e $15 \mathrm{~mm}$ o refino geral. Ainda de acordo com essa figura, a direção $X$ corresponde à direção de laminação. As condições de contorno do modelo foram aplicadas em duas etapas: primeiramente é necessário restringir a movimentação indesejada do conjunto, para isso foi aplicada uma condição de simetria em relação ao eixo $x$ na aresta inferior da chapa e uma condição de pino no ponto de referência adicionado ao centro do cilindro. A segunda parte consiste e aplicar a movimentação esperada do conjunto, em relação ao cilindro de trabalho. Foi aplicada uma velocidade angular constante no valor de 45,94 rad/s como condição inicial que foi propagada ao longo do step. Em relação à chapa foi aplicada uma velocidade linear na direção x no valor de $700 \mathrm{~m} / \mathrm{min}$ como condição inicial que foi suprimida ao longo do step, pois a velocidade angular do cilindro é a responsável por manter a velocidade linear da chapa ao longo da simulação.

Com relação à curva de escoamento do material da chapa, foi utilizado um gráfico com várias curvas dependentes da velocidade de deformação (Figura 3), que, conforme mencionado anteriormente, produz grandes variações no resultado da carga de laminação. Trata-se de um aço baixo-carbono recozido, com tensão de escoamento inicial semelhante ao do material simulado. A inserção das curvas foi feita por meio de tabelas contendo três colunas,

Tabela I. Dados geométricos do laminador de encruamento

\begin{tabular}{lcll}
\hline \multicolumn{1}{c}{ Parâmetros } & \multicolumn{1}{c}{ Parâmetros } \\
\hline Espessura de entrada $(\mathrm{mm})$ & 0,248 & Módulo de elasticidade da chapa $(\mathrm{GPa})$ & 200 \\
Espessura de saída $(\mathrm{mm})$ & $0,24 \mathrm{I}$ & Módulo de elasticidade do cilindro $(\mathrm{GPa})$ & 210 \\
Alongamento $(\%)$ & 2,89 & Coeficiente de Poisson, chapa & 0,3 \\
Diâmetro do cilindro de trabalho $(\mathrm{mm})$ & 508 & Coeficiente de Poisson, cilindro & 0,3 \\
Largura da chapa $(\mathrm{mm})$ & 885 & Coeficiente de atrito & 0,158 \\
Tensão à frente $(\mathrm{MPa})$ & 126,6 & Velocidade de laminação $(\mathrm{m} / \mathrm{min})$ & 700 \\
Tensão à ré $(\mathrm{MPa})$ & 56,8 & Carga de laminação medida $(\mathrm{t})$ & 1.183 \\
\hline
\end{tabular}

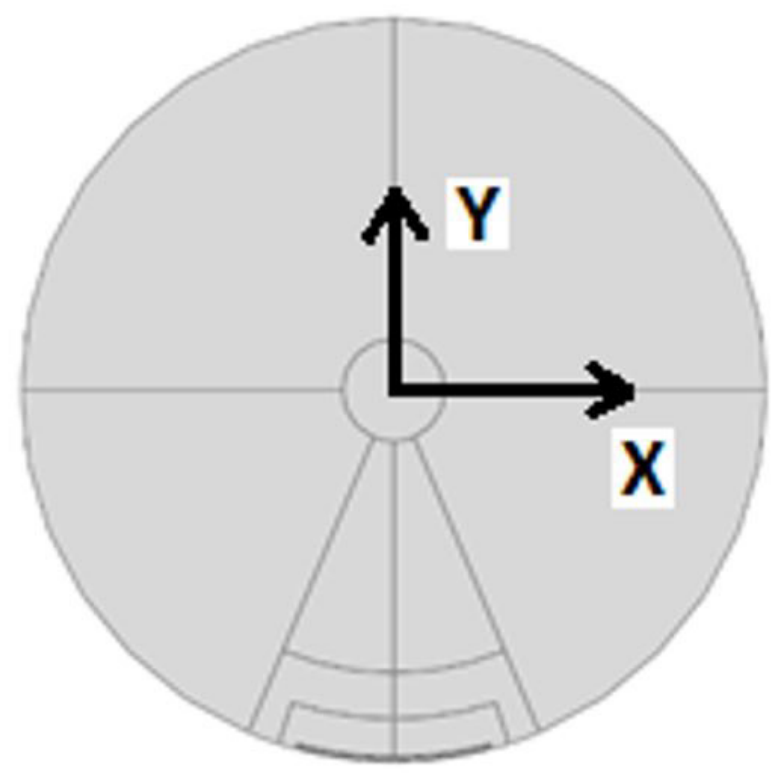

Figura I. Cortes aplicados ao cilindro para geração da malha de elementos finitos. 


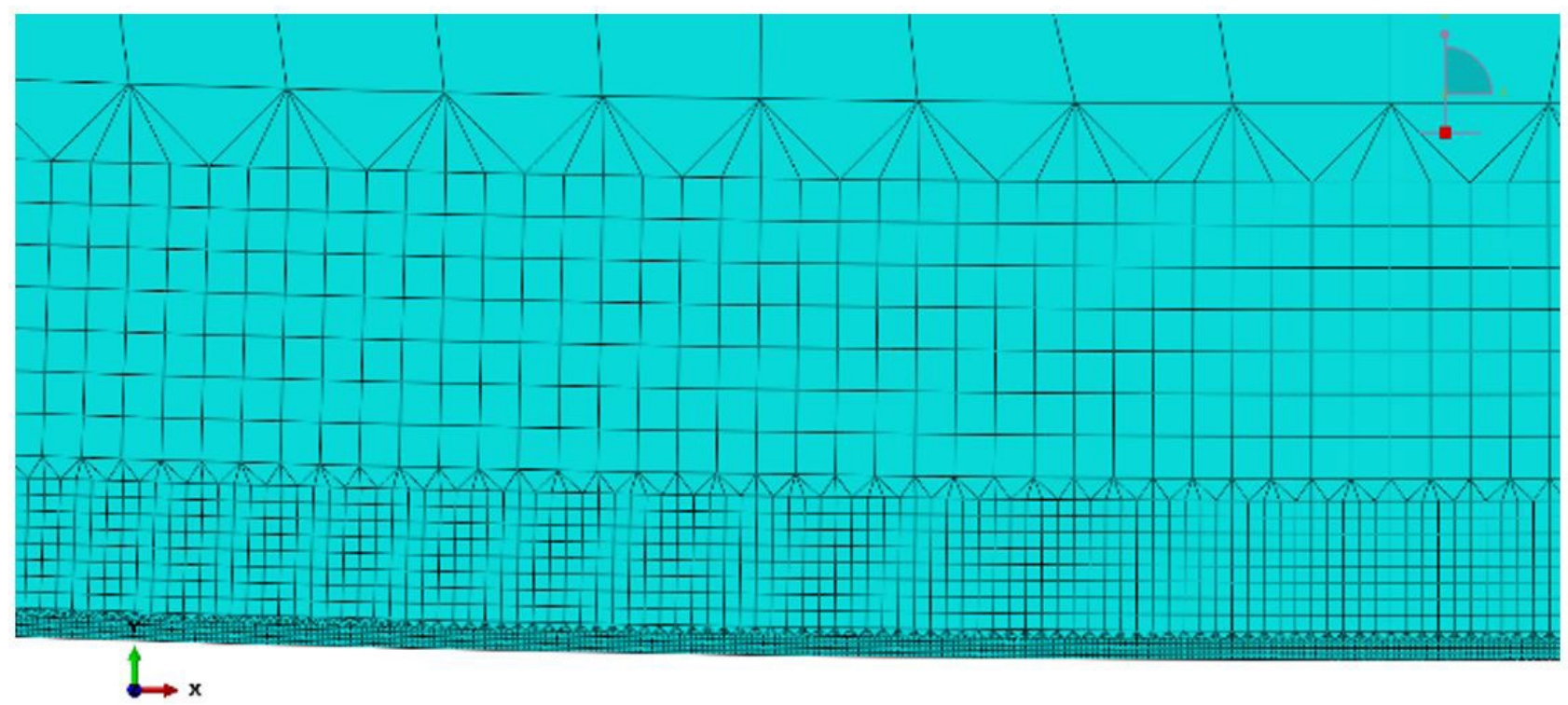

Figura 2. Detalhes dos elementos utilizados na área de transição.

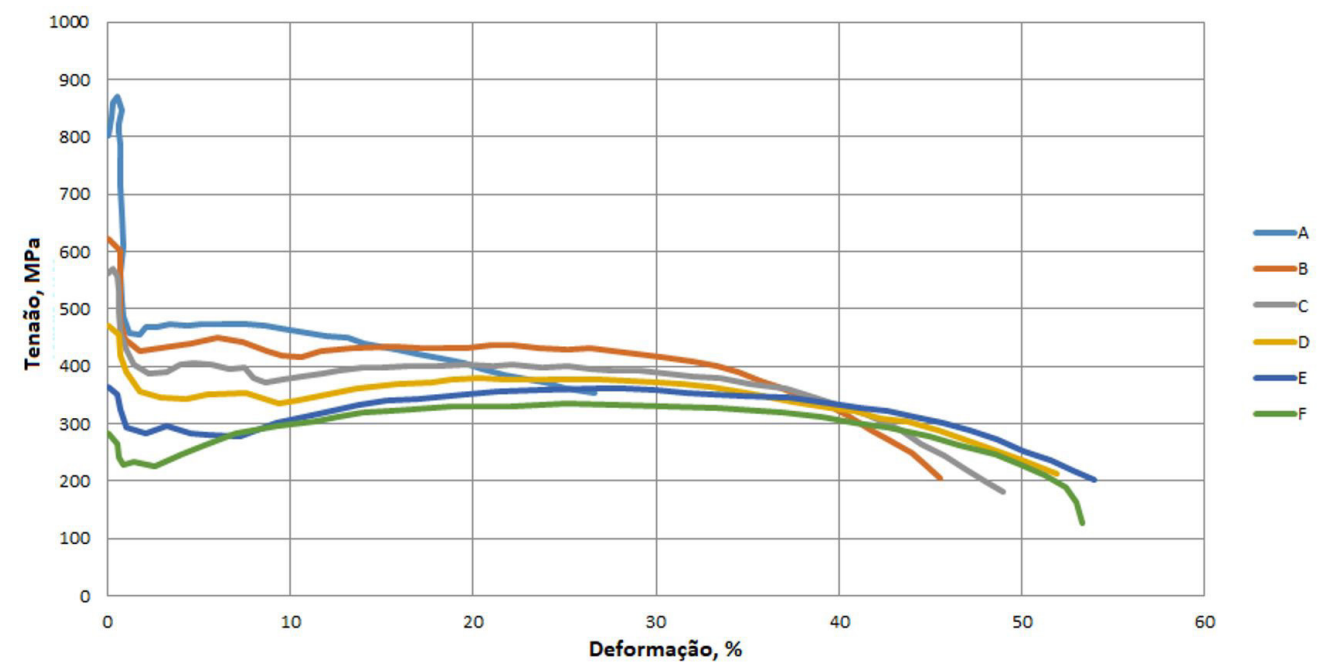

Figura 3. Curvas de escoamento para um aço baixo-carbono e diferentes velocidades de deformação (A: I750 s $\mathrm{s}^{-1} ; \mathrm{B}: 106 \mathrm{~s}^{-1} ; \mathrm{C}: 55 \mathrm{~s}^{-1} ; \mathrm{D}: 10 \mathrm{~s}^{-1}$; E: $2 s^{-1} ; \mathrm{F}: 0,001 \mathrm{~s}^{-1}$ ) (Adaptado de [I0]).

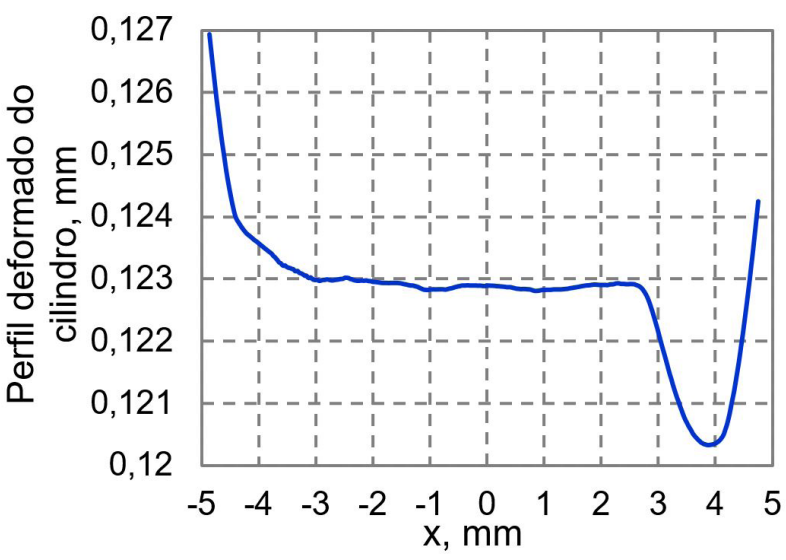

Figura 4. Deformação do cilindro. a saber, a da deformação verdadeira, tensão e velocidade de deformação.

A simulação realizada neste trabalho foi uma simulação dinâmica explicita para simular um período de 0,0 I segundos do processo de laminação, com incremento de tempo e o fator de mass scaling calculados automaticamente pelo software.

\section{RESULTADOS}

Empregando os dados da Tabela I e das curvas tensão vs. deformação da Figura 3, obteve-se um arco de contato de 8,56 mm de comprimento e uma região plana, conforme observado pela Figura 4. A Figura 5 apresenta a colina de atrito, ou pressão normal que ocorre na interface 


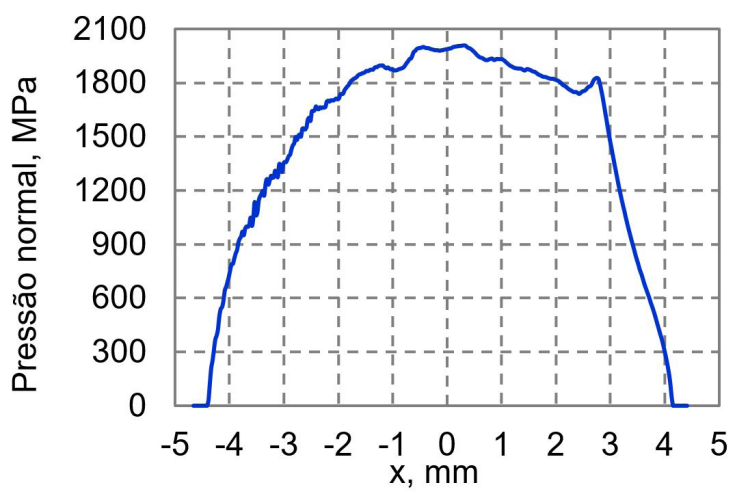

Figura 5. Pressão normal no arco de contato.

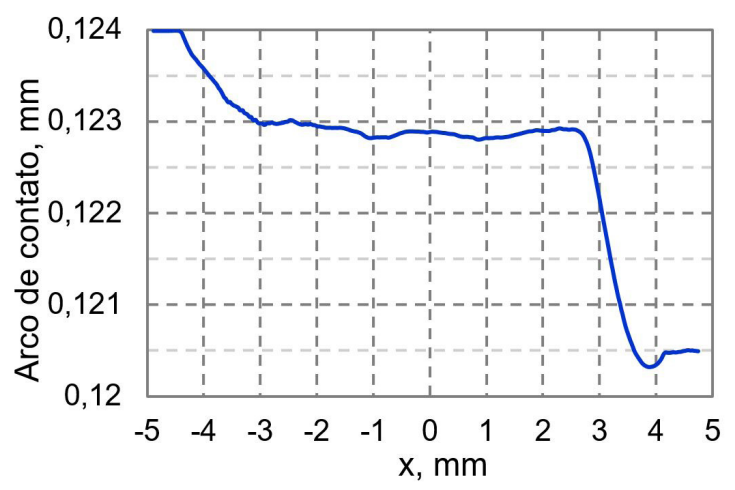

Figura 6. Arco de contato.

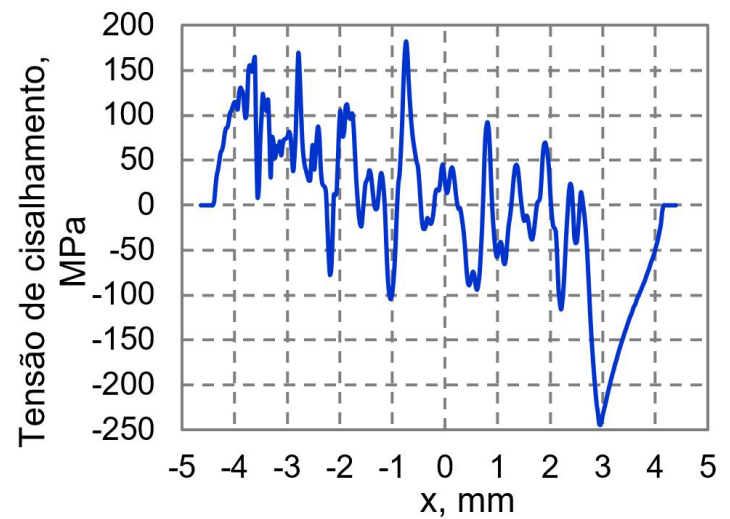

Figura 7. Tensão de cisalhamento na superfície do arco de contato. cilindro de trabalho/chapa bastante diferente do previsto em modelos como Bland-Ford e de Roberts [I]. A partir desse resultado calculou-se a carga de laminação, resultando em I. I8I t, um pouco inferior ao valor medido, de I. I83 t. Um cálculo rápido pelo método simplificado proposto por Roberts resultou em somente 2 | 4,7 t, valor muito abaixo do calculado. Isso se deve, em parte, à hipótese de Roberts sobre o perfil parabólico da colina de atrito, o que não é o caso, e de estimar o arco de contato em somente $2,02 \mathrm{~mm}$. Cabe observar que se conseguiu atingir a espessura final de 0,247 $\mathrm{mm}$ experimental graças à aplicação de uma abertura entre cilindros negativa de 0,129 mm (a Figura 6 apresenta a metade superior da chapa na região do arco de contato). Pode-se observar na Figura 7 a distribuição de tensões de cisalhamento na superfície do arco de contato. A Figura 8 apresenta a distribuição de tensões de von Mises dentro do arco de contato, e observam-se extensas regiões encruadas.

\section{CONCLUSÃO}

Pelos resultados pode-se concluir que o modelo em elementos finitos produz resultados precisos que permitem obter uma maior compreensão do processo. A carga de laminação calculada, valor importante para controle do processo, igualou-se ao medido. Pelas Figuras 4 e 6 pode-se observar um comprimento longo de arco quase horizontal devido ao elevado achatamento elástico do cilindro de trabalho. Outro aspecto muito interessante da simulação em elementos finitos se refere à distribuição das tensões internas na chapa e o aspecto do arco de contato. Pode-se observar uma região larga encruada dentro do arco, e não somente na superfície da chapa, na cor vermelha da Figura 7. Também se observa uma região relativamente plana dentro do arco de contato, demonstrando o largo achatamento do cilindro de trabalho ao longo de $8,56 \mathrm{~mm}$ de arco de contato. Por fim, observa-se que o modelo de cálculo de carga de Roberts não serve para estas condições de operação reais.

\section{Agradecimentos}

Nossos agradecimentos ao CEFET-MG pelo auxílio a este projeto.

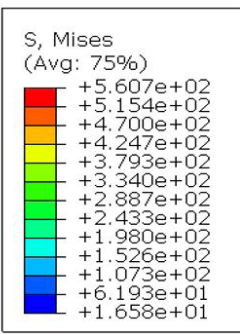

Figura 8. Distribuição de tensões de von Mises dentro do arco de contato.

Tecnol. Metal. Mater. Miner., São Paulo, 


\section{REFERÊNCIAS}

I Roberts W. Hot rolling of steel. Boca Raton: Chapman and Hall/CRC; 1983.

2 Lenard J. Primer on flat rolling. 2nd ed. Kidlington: Elsevier; 2014.

3 Liu Y, Lee WH. Application of the preliminary displacement principle to the temper rolling model. KSME International Journal. 2001; I5(2):225-23I.

4 Pawelski $\mathrm{H}$. Modelling of temper rolling considering surface change of strip, 8th International Conference on Metal Forming, 2000. In: Lenard J. Primer on flat rolling. 2nd ed. Kidlington: Elsevier; 20I4. p. 30I-302.

5 Dbouk T, Montmitonnet P, Suzuki N, Takahama Y, Legrand N, Ngo T, et al. Advanced roll bite models for cold and temper rolling processes. In: Associazione Italiana di Metallurgia. Proceedings 9th International Rolling Conference \& 6th European Rolling Conference; 2013 June 10-12; Venice, Italy. Milano: AIM; 20I3. p. I-I6.

6 Shigaki Y, Nakhoul R, Montmitonnet P. Numerical Treatments of Slipping/No-Slip Zones in Cold rolling of thin sheets with heavy roll deformation. Lubricants. 20I5;3(2):II3-I3I.

7 Kainz A, Krimpelstätter K, Zeman K. FE-Simulation of thin strip and temper rolling processes. In: Proceedings of the ABAQUS Austria User's Conference; 2003 November 24-25; Vienna, Áustria. Vienna: ABAQUS; 2003. p. I-8.

8 Gratacos P, Montmitonnet P, Fromholz C, Chenot JL. A plane-strain elastoplastic finite-element model for cold rolling of thin strip. International Journal of Mechanical Sciences. 1992;34(3): 195-2 10.

9 Shigaki Y, Silva JM, Romie RNA, Magalhães FC, Pessanha L. Elastoplastic finite element analysis of the temper rolling process. Revista Interdisciplinar de Pesquisa em Engenharia. 2016;2(23):297-319.

10 Blazynski TZ. Materials at high strain rates. London: Elsevier Applied Science; 1987.

Recebido em: 30 Nov. 2018

Aceito em: 05 Jul. 2019 